\title{
Mir-139 Regulates Autophagy in Prostate Cancer Cells Through Beclin-1 and mTOR Signaling Proteins
}

\author{
ROBERT K. NAM ${ }^{1}$, TANIA BENATAR ${ }^{2}$, YUTAKA AMEMIYA ${ }^{3}$, \\ CHRISTOPHER SHERMAN ${ }^{4}$ and ARUN SETH ${ }^{2,3,4,5}$
}

\author{
${ }^{1}$ Division of Urology, Sunnybrook Health Sciences Centre, University of Toronto, Toronto, ON, Canada; \\ ${ }^{2}$ Platform Biological Sciences, Sunnybrook Research Institute, University of Toronto, Toronto, ON, Canada; \\ ${ }^{3}$ Genomics Core Facility, Sunnybrook Research Institute, University of Toronto, Toronto, ON, Canada; \\ ${ }^{4}$ Department of Laboratory Medicine and Pathobiology, \\ Sunnybrook Research Institute, University of Toronto, Toronto, ON, Canada; \\ ${ }^{5}$ Faculty of Dentistry, University of Toronto, Toronto, ON, Canada
}

\begin{abstract}
Background/Aim: We previously identified a panel of five miRNAs (including miR-139) associated with biochemical recurrence and metastasis in prostate cancer patients. Materials and Methods: We examined miR-139 transfected PC3, DU145 and LNCaP cells by morphology as well as by cell-based assays, confocal microscopy and immunoblotting. Results: We found that treatment of prostate cancer cells with miR-139 resulted in phenotypic changes characteristic of autophagic cells. MiR-139 increased the autophagy-related conversion of the microtubuleassociated protein light chain 3 (LC3-I to LC3-II) that was specifically inhibited by the miR-139 antagomir. The upregulation of LC3 II was further confirmed by confocal microscopy. miR-139 regulated activation of both mTOR and Beclinl the two important autophagy-related molecules. We found that upon miR-139 treatment, the cargo adaptor protein p62 which is degraded during autophagy, accumulates. Conclusion: These results suggest that miR-139 is inducing autophagic flux blockade leading to apoptosis in prostate cancer cells through the mTOR and Beclin-1 proteins.
\end{abstract}

Prostate cancer $(\mathrm{PCa})$ is the second most common cancer in the world among men and the fifth most common cause of cancer-

This article is freely accessible online.

Correspondence to: Arun Seth, Ph.D., Professor, Department of Laboratory Medicine and Pathobiology, University of Toronto Director, Molecular Diagnostics Academic Director, Genomic Core Senior Scientist, Biological Sciences Sunnybrook Research Institute, University of Toronto, 2075 Bayview Av., Toronto, M4N 3M5 ON, Canada. Tel: +1 4164806100 ext. 3536, e-mail: arun.seth@utoronto.ca

Key Words: LC3B-II, SQSTM1, apoptosis, chloroquine, miR-139, autophagy, Beclin-1, mTOR, prostate cancer. related death among men worldwide. It is a heterogeneous disease, where the majority of cases present as indolent, while some experience a highly aggressive form which metastasizes, often leading to mortality (1). The 5-year survival rate for most men with local or regional prostate cancer is almost $100 \%$. However, for men diagnosed with metastatic prostate cancer, the 5-year survival rate is $29 \%$ (2). A grading system known as Gleason score (GS) is used as a guide together with several other factors to determine the aggressiveness of the cancer and the potential type of treatments that may be implemented. Tumors with lower GS indicate cells that are similar to normal cells and are less likely to be aggressive. In contrast, tumors with higher GS scores are indicative of tumors with poorly differentiated cells, which tend to be more aggressive (3). The prostate-specific antigen testing (PSA) is another method used to screen for PCa. However, this method has become controversial due to high rates of overdiagnosis and overtreatment (4). PSA-based screening is also associated with significant underdiagnosis of clinically significant disease. Therefore, there is a significant need for biomarkers to distinguish between PCa patients who will have an indolent versus aggressive form of cancer. MicroRNAs(miRs) are highly conserved small noncoding RNAs that control gene expression and regulate biological processes by targeting messenger RNAs (mRNAs) through inhibition or degradation (5). Altered expression of miRNAs has been reported in $\mathrm{PCa}(6)$.

Through whole miRNome sequencing, we identified a panel of five miRNAs from 33, miRs-301a, 652, 454, 223, and 139 , that were associated with PCa recurrence and metastasis following prostatectomy (7). Three of these miRNAs were overexpressed, while two were underexpressed in prostate tumors. We previously determined the mechanism of action of miRNAs that were up-regulated in our panel, miR-301a, miR454 , and miR-652 $(8,9)$. We recently investigated the mechanism of action of one of the down-regulated miRNAs, 
miR-139-5p (10). We found that miR-139 inhibits PCa cell growth by down-regulating two different targets, AXL and IGF1R. AXL down-regulation was associated with inhibition of the PI3K/AKT pathway and the PLC $\gamma 1 / \mathrm{PKC} \alpha$ pathway, leading to cell-cycle arrest. In this study, we further investigated the molecular mechanism of miR-139-mediated suppression of $\mathrm{PCa}$ cell growth through regulation of autophagy. Autophagy is a highly conserved, homeostatic process by which intracellular constituents are delivered to lysosomes for degradation (11). However, under specific conditions, autophagy can directly or indirectly induce cell death. Our study showed that miR-139 treatment of PCa cells induces autophagic flux blockade and simultaneous induction of apoptosis.

\section{Materials and Methods}

Cell lines. Prostate cancer cell-lines were purchased from American Type Culture Collection (ATCC). PC3 prostate cancer cells were maintained in Dulbecco's Modified Eagle Medium/Nutrient Mixture F-12 (DMEM/F-12) (Wisent) and DU145 prostate cancer cells were maintained in Dulbecco's modified Eagle's medium (DMEM) (Wisent), all supplemented with $10 \% \mathrm{FBS}$ at $37^{\circ} \mathrm{C}$ in a $5 \% \mathrm{CO}_{2}$ atmosphere.

Transient transfection. PC3, Du145 or LNCaP cells were seeded in six-well plates for $24 \mathrm{hrs}$. Immediately before transfection, regular media was replaced with media containing 5\% FBS. Transfections were performed using Lipofectamine RNAiMAX (Thermo Fisher Scientific, Manassas, VA, USA) according to the manufacturer's recommendations. Transfections were performed with $25 \mathrm{pmol} / \mathrm{well}$ of either miR-139-5p mimic (MSY0000250; Qiagen) or negative control mimic (AllStars Negative Control siRNA; Qiagen, Hilden Germany). For blocking experiments, $50 \mathrm{pmol} /$ well of anti-hsa-miR$139-5 p$ miScript miRNA inhibitor (Qiagen) were added per well. Chloroquine was added to cells by incubating with $50 \mu \mathrm{M}$ final concentration overnight.

Immunofluorescence. PC3-treated cells were grown on coverslips in 24 well plates for 3 days, then fixed in $100 \%$ cold methanol for 5 min, permeabilized with $0.2 \%$ Triton X-100 prepared in PBS for 15 min at room temp, blocked and immunostained with rabbit antiLC3B antibody in $1 \%$ BSA PBST (PBS+0.1\% Tween 20), followed by $\mathrm{Cy} 3$-conjugated donkey-anti-rabbit IgG. Nuclei were revealed by DAPI staining. Fluorescent images were observed and collected under a Nikon A1 inverted confocal microscope. Images were quantitated using Image $\mathrm{J}$ software version 1.51.

Western blotting. Cell extracts were prepared by lysis in RIPA buffer in the presence of proteinase and phosphatase inhibitors. The cell lysates were collected by centrifugation at $20,000 \mathrm{~g}$ for $15 \mathrm{~min}$ at $4^{\circ} \mathrm{C}$ and protein content in the supernatant was measured using the Bradford protein assay (BioRad, Irvine, CA, USA). Approximately $5-10 \mu \mathrm{g}$ of protein were separated on either 8 or $15 \%$ SDSpolyacrylamide gels and electroblotted on to nitrocellulose membranes. Membranes were blocked with 5\% nonfat dry milk:TBS-T [20 mmol/l Tris- $\mathrm{HCl}(\mathrm{pH} 8.0), 137 \mathrm{mmol} / \mathrm{l} \mathrm{NaCl}$ and $0.1 \%$ Tween 20] or 5\% BSA for one $\mathrm{h}$ at RT, and incubated with the primary antibodies overnight at $4^{\circ} \mathrm{C}$. After washing with TBS-T, blots were probed with HRP-conjugated secondary antibodies for 1 $\mathrm{h}$ at RT. The blots were then washed and treated with ECL reagent (1M Tris $\mathrm{pH} 8.5,198 \mu \mathrm{M}$ para-coumaric acid, $1.25 \mathrm{mM}$ luminol, $0.009 \% \mathrm{H}_{2} \mathrm{O}_{2}$ ) and the protein bands were visualized using Kodak XOMAT- AR film for autoradiography. The following monoclonal and polyclonal antibodies were used: anti-LC3B, anti-cleaved PARP-1, anti-phospho-mTOR(Ser2448), anti-mTOR (Cell Signaling); anti-p62/SQSTM1(D-3), anti-beclin 1(E-8), anti-pp38(E1), anti-p38 $\alpha(9 \mathrm{~F} 12)$ (Santa Cruz Biotech); anti-beclin-1 (phosphoSer93/96)(Signalway Antibody); anti- $\beta$-tubulin (Sigma-Aldrich), and HRP conjugated goat anti-mouse and goat anti-rabbit (Promega). Image $\mathrm{J}$ version 1.51 was used for densitometry of Immunoblots.

Cell death determination. Cells were counted by dilution in trypan blue. Percentage of dead cells were calculated by counting the number of blue-labeled cells, and expressing them as a percentage of total cells (both live and dead).

Ion AmpliSeq transcriptome sequencing. The transcriptome sequencing of miR-139 over-expressing and empty vector transfected PC3 and Du145 cell lines were performed on the Ion S5XL Next Generation Sequencing system with the Ion AmpliSeq Transcriptome Human Gene Expression Kit (ThermoFisher Scientifics). The cDNA was synthesized from 10ng of total RNA by SuperScript VILO cDNA Synthesis Kit (Thermofisher Scientific). The cDNA libraries were constructed by Ion Ampliseq Library Kit Plus and the sequencing template preparation was done by using Ion Chef with Ion 540 Chef Kits. Sequencing was performed for 500 flows on an Ion S5XL Sequencer with Ion 540 chip. The differential gene expression analysis between samples and pathway enrichment analysis of differentially expressed genes was performed by Transcriptome Analysis Console (TAC) Software 4.0.2 (ThermoFisher Scientific).

Statistical analysis. All statistical analysis was conducted using Excel (version 2007). Student's $t$-test was used to obtain $p$-values for comparison of two groups. All graphs show mean $\pm \mathrm{SD}$ of triplicate experiments.

\section{Results}

Mir-139 induces morphology changes in PC 3 and Dul45 cells. Previously, we showed that PC3 and Du145 cells treated with miR-139 displayed growth inhibition compared to their negative mimic treated counterparts (10). We examined the morphology of these treated cells in an attempt to understand further the growth inhibitory mechanism of miR-139. Transient transfection of PC3 cells with miR-139 for 5 days revealed dramatically different morphologies. Cells appear to have lost the rounded epithelial form, becoming larger, with cytoplasmic ballooning, displaying abnormal shapes which range from elongated to having spiky projections. In addition, the miR-139 PC3 transfected cells accumulated numerous rounded vacuoles within them, which are typically seen in cells undergoing autophagy (12). PC3 cells transiently transfected with negative control mimic appeared to grow in their typical adherent spherical epithelial morphology (Figure 1). Du145 cells treated 

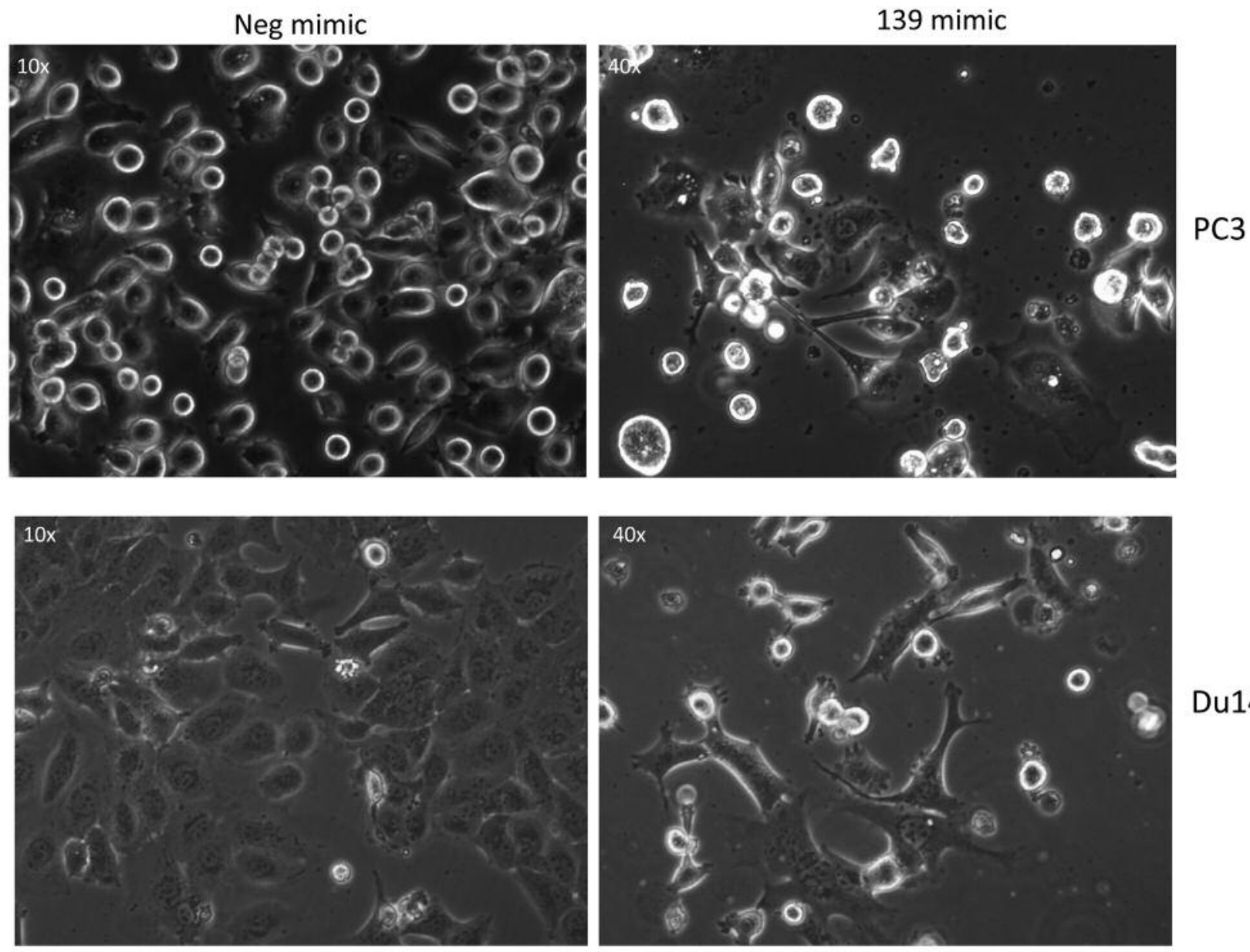

Du145

Figure 1. PC3 and Du145 cells were transiently transfected with either miR-139 or negative (neg) mimic for 2 days followed by reseeding and retransfecting for 3 more days. Cells were then visualized by light microscopy at 10x and 40x magnification for morphology changes. Images are representative of at least 3 independent experiments.

with miR-139 also undergo morphology changes, with abnormal shapes which include elongation and spiky projections. However, no vacuoles were observed compared to PC3-miR-139 treated cells.

Up-regulation of autophagic markers by miR-139. Morphology changes reminiscent of autophagy in PC3 cells treated with miR-139 prompted us to examine whether markers of autophagy are expressed upon miR-139 treatment. Autophagy is a multistep process in which the formation of the autophagosome requires the sequential modification of the microtubule-associated protein 1 light chain 3 beta (LC3B). LC3B is first cleaved to produce LC3B-I. Upon induction of autophagy, a fraction of LC3B-I is transferred to phosphatidylethanolamine (PE) to produce LC3B-II (13). LC3B-II associated with the autophagosome and therefore the amount of LC3B-II and the formation of
LC3B puncta, representing autophagic vesicles, are the cornerstone of the autophagosome (14). These puncta can be visualized by confocal microscopy.

In order to determine whether miR-139 was inducing autophagy in PC3 cells, we examined LC3B punctuate formation in PC3 cells treated for 3 days with either negative or miR-139 mimic by confocal microscopy. As a positive control for autophagy induction, chloroquine (CQ) $(50 \mu \mathrm{M})$ treatment was also included. Results revealed that miR-139 mimic increased LC3B puncta to similar levels as CQ treatment, while a diffuse, cytoplasmic red fluorescence was observed in control cells (Figure 2A). Quantification of puncta confirmed that miR-139 significantly up-regulated LC3B expression in PC3 cells as compared to negative mimic (Figure 2B).

LC3B-I to LC3B-II conversion is an important indicator of autophagy activity (13). To confirm that LC3B-II was up- 

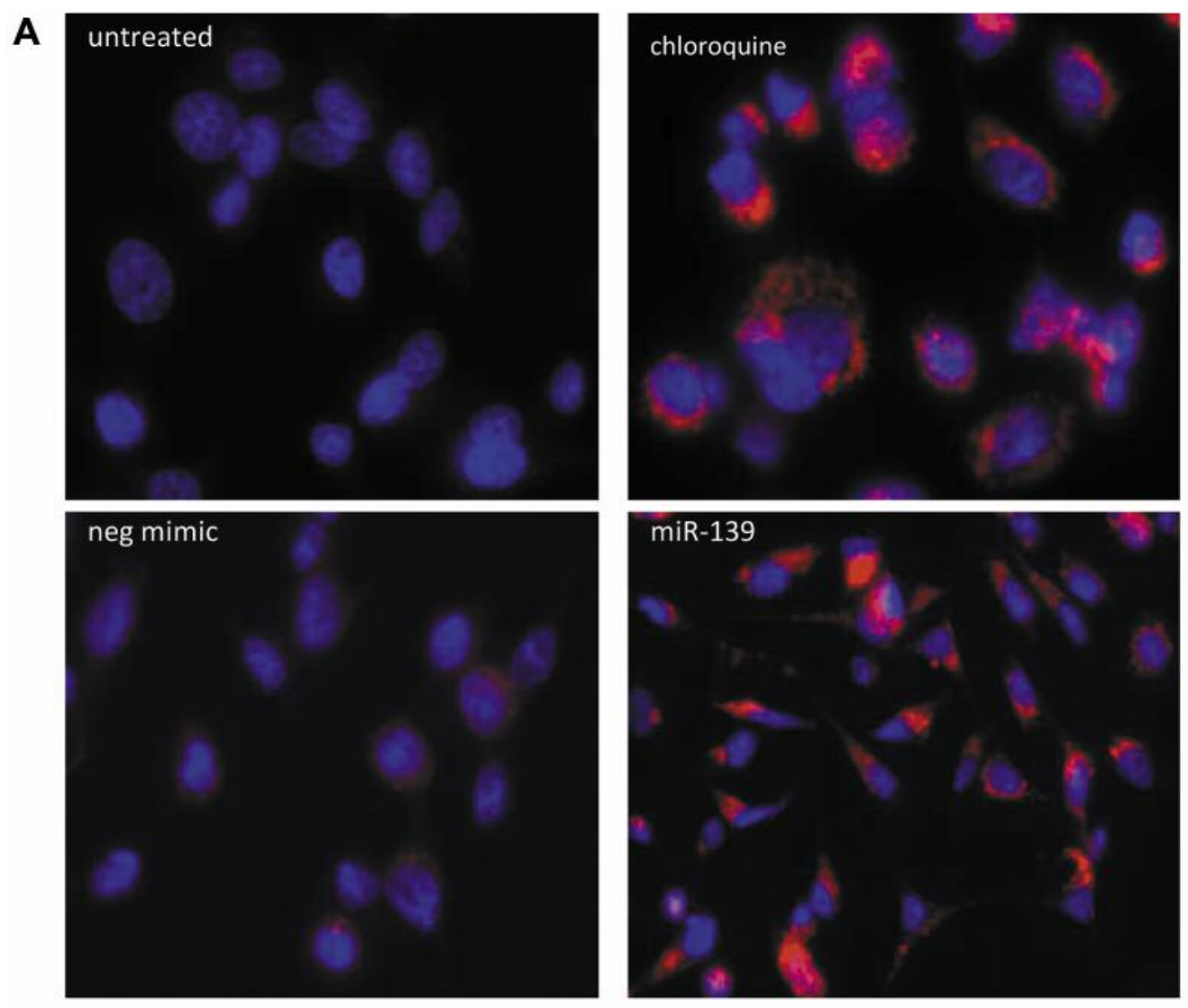

B

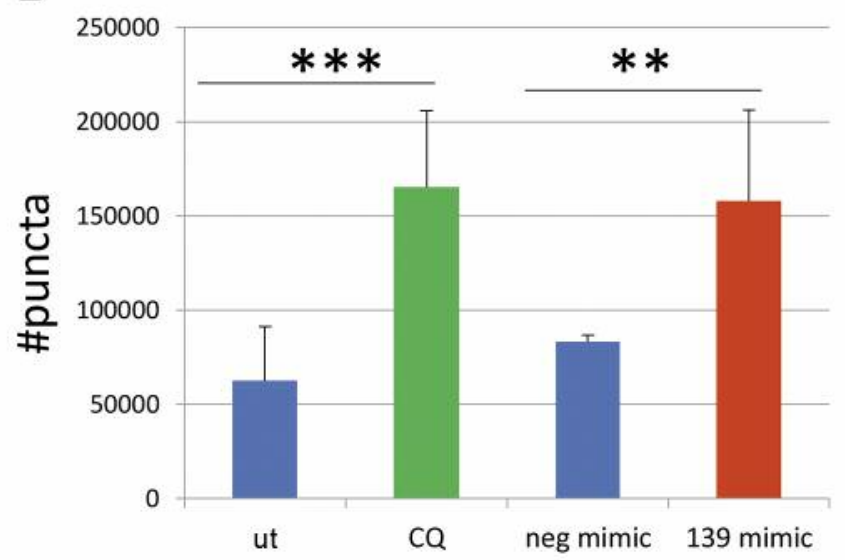

Figure 2. (A) PC3 cells were plated on coverslips overnight, and then transiently transfected with either 25 pmol/well of either miR-139 mimic or negative control mimic (neg) for 3 days with Lipofectamine RNAimax, or chloroquine $(C Q)(50 \mu M)$ overnight. Untreated cells were included as control for CQ. Coverslips were fixed, permeabilized and then stained with anti-LC3B antibody, followed by Cy3-conjugated donkey-anti-rabbit IgG. Nuclei were visualized by counterstaining with DAPI. After mounting coverslips on slides, fluorescent images were visualized using confocal microscopy $(B)$. Quantification of LC3B puncta were performed using Image J software. (ut) refers to untreated cells; p-values were determined by the unpaired t-test $(* p<0.05 ; * * p<0.01 ; * * * p<0.001)$.

regulated by miR-139, we examined the expression of LC3B-II by western blotting (WB). PC3 cells were transiently transfected with miR-139 mimics or negative mimics for 1-3 days. At each timepoint, lysates were examined by WB for LC3B-II expression. LC3B-II protein expression was significantly increased by miR-139 treatment (Figure 3A). Quantification of the WB by densitometry revealed that the miR-139 significantly increased LC3B-II 
A

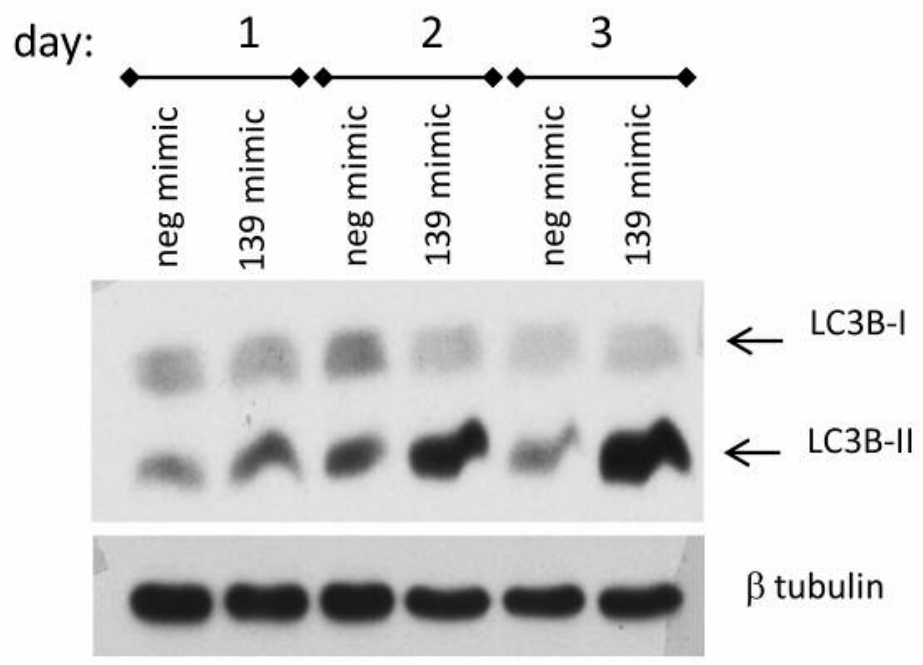

C

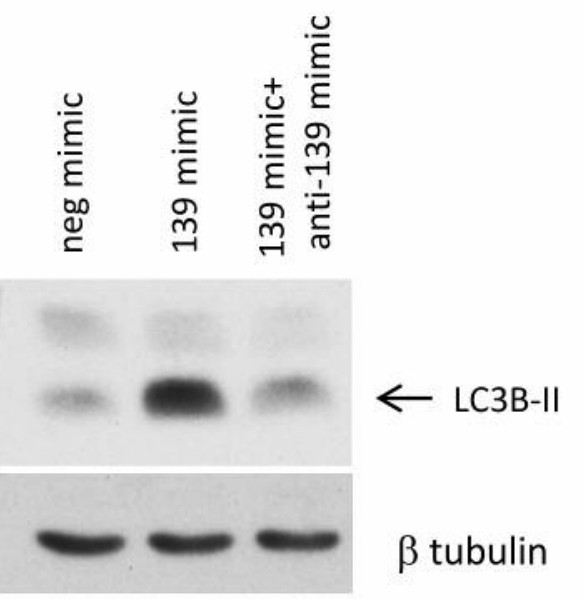

E

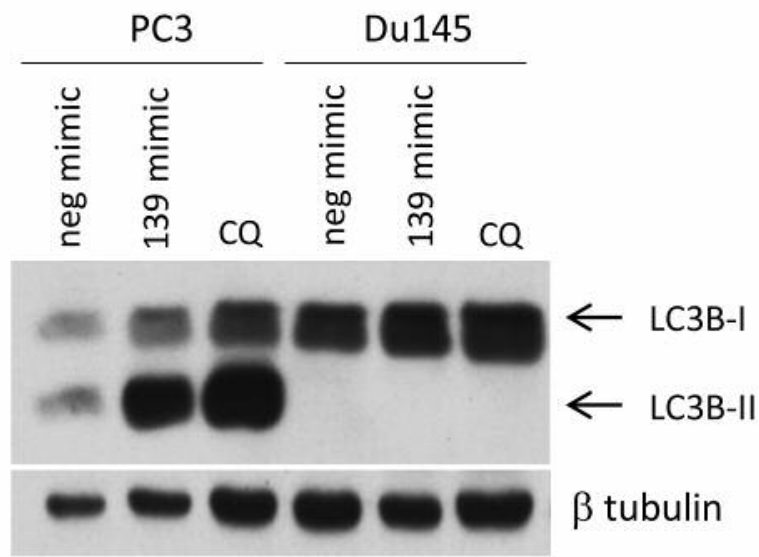

B

LC3B-II/ $\beta$ tubulin

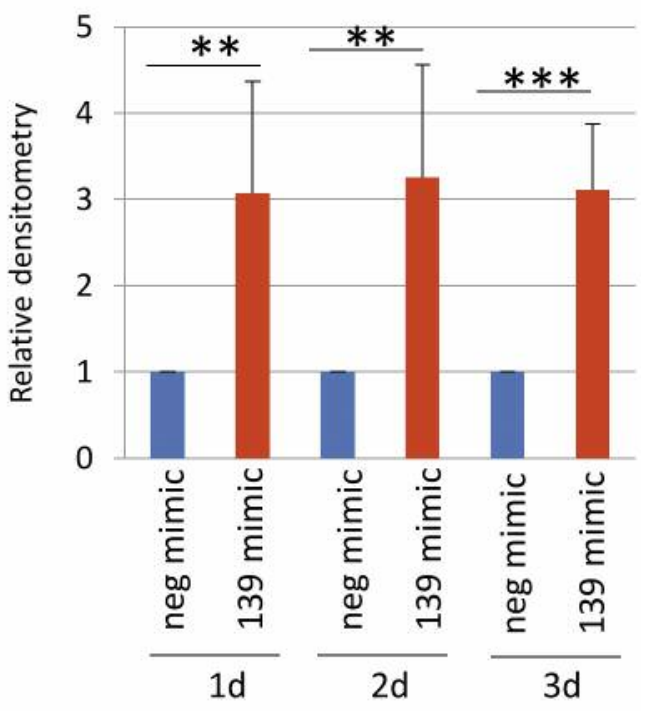

D

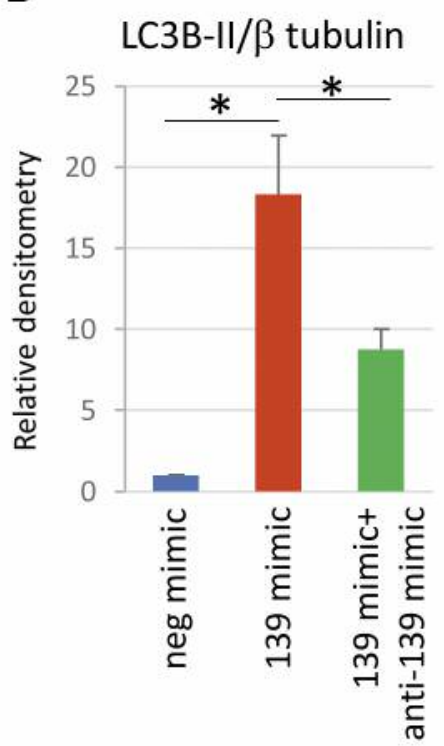

Figure 3. (A) PC3 cells were transiently transfected with either 25 pmol of miR-139 mimic or negative control (neg) mimic for 1, 2 and 3 days. On each day, western blots $(W B)$ were performed on cell lysates with specific antibodies. WB is representative of at least 3 separate experiments. (B) $W B$ were quantified using by densitometry. Protein levels of LC3B-II were compared to $\beta$ tubulin loading control. Blue bars represent transfection with neg mimic; red bars represent transfection with miR-139. Data are presented as a mean $+S D$ of the mean of three independent experiments and $p$-values determined by the unpaired t-test $\left({ }^{*} p<0.05 ; * * p<0.01\right.$; ***p<0.001). (C) PC3 cells were transiently transfected for 3 days with either 25 pmol of miR-139, neg mimic or 25 pmol of miR-139 combined with 50 pmol of miR-139 antagomir (anti-139 mimic). (D) WB from $(C)$ was quantified by densitometry. $P$ values were determined as per $(B) .(E)$ $P C 3$ or Du145 cells were transiently transfected for 4 days with either miR-139 mimic, neg mimic or overnight with $C Q(50 \mu M)$. WB were performed using anti-LC3B antibody, and stripped and reprobed with $\beta$ tubulin for loading control. 
expression at all 3 time points (Figure 3B). To confirm that increased LC3B-II expression was due to miR-139 treatment, PC3 cells were treated for 3 days with either miR-139 alone, neg mimic alone, or miR-139 and antagomir to miR-139. WB reveals that the increased expression of LC3B-II by miR-139 was abrogated when antagomir to 139 was added (Figure 3C and D). In contrast to miR-139 treatment of PC3 cells, treatment of Du145 cells with miR-139 for 4 days was unable to induce expression of LC3B-II (Figure 3E). To confirm that the inability to up-regulate LC3B-II expression in Du145 was not limited to miR-139 treatment, both PC3 and Du145 were treated overnight with CQ. CQ inhibits autophagy flux by raising the $\mathrm{PH}$ within the lumen of lysosomes and/or autolysosomes and therefore compromises autophagic degradation, leading to the accumulation of LC3B-II (16). While LC3B-II was also increased by CQ treatment in PC3 cells, no LC3B-II was observed in Du145 cells, whether treated with miR-139 or CQ (Figure 3E). This observation was not unexpected as Du145 cells lack one or two exons in ATG5, which interferes with the formation of LC3B-II, and thus impairs autophagy in that cell-line (15).

Beclin 1 was one of the first mammalian autophagy proteins identified, regulating both autophagosomal synthesis and autophagosome maturation (16-19). Beclin 1 is activated through post-translational modifications such as phosphorylation, ubiquitination and cleavage, allowing it to fine-tune PI3K-III activity and autophagy (20). To further verify that miR-139 was inducing autophagy, we examined beclin 1 phosphorylation upon miR-139 expression. miR-139 treatment induced beclin 1 phosphorylation (Figures 4A and B). This increase was shown to be dependent on miR-139 expression, as treatment with both miR-139 mimic and miR139 antagomir abrogated phospho-beclin 1 expression induced by miR-139 alone (Figures 4C and D). Treatment of Du145 cells for 3 days with miR-139 did not increase expression of phospho-beclin 1 compared to negative mimic (Figure 4E). Thus, the lack of functional ATG5 in Du145 cells may be also affecting beclin 1 activation.

miR-139 down-regulates the PI3K/Akt/mTOR pathway to suppress autophagy. The PI3K/Akt pathway is known to inhibit autophagy through the activation of mammalian target of rapamycin (mTOR) $(21,22)$. We have previously shown that miR-139 treatment of PC3 cells inhibits Akt activation (10). To further examine the mechanism of autophagy induction by miR139 in prostate cancer cells, the activation of mTOR was analyzed. As shown in Figure 5A, miR-139 mimics were able to down-regulate the expression of p-mTOR in PC3 cells compared to control mimics at the protein level. Furthermore, not only was activation of mTOR affected, but total protein expression of mTOR was also down-regulated by miR-139 treatment (Figure 5A and B). Collectively, these data indicate that miR-139-mediated Akt/mTOR pathway inhibition enhances the autophagy of PC3 cells. We previously demonstrated that miR-139 treatment of Du145 resulted in Akt activation (10). We examined mTOR activation in Du145 after miR-139 treatment for 4 days. MiR-139 treatment also inhibited p-mTOR and mTOR protein expression in Du145 cells (Figure 5C and D). Since both p-mTOR and mTOR protein levels are both inhibited by miR-139, the relative ratio of p-mTOR to mTOR remains unchanged, suggesting that miR-139 effects are targeting the absolute levels of mTOR rather than its activation. In support of this, whole transcriptome analysis of miR-139treated PC3 and Du145 prostate cancer cells demonstrated significant down-regulation of mTOR mRNA expression (Figure 5E). Thus, down-regulation of mTOR both at the protein and mRNA level likely contributed to the increased autophagy observed by miR-139 treatment.

MiR-139 induces autophagic flux blockade in prostate cancer cells. p62/SQSTM1, the first identified autophagy adaptor, recognizes ubiquitinated cargoes and recruits them to the autophagosomal membrane via its LC3-interacting region $(23,24)$. The level of p62 has been used for monitoring autophagy flux, since it accumulates in cells when autophagy is blocked (25). Transfection of PC3 cells with miR-139 for shorter time periods such as 2 days resulted in reduced p62 protein expression compared to neg mimic (Figure 6A). However, retransfection of 2 day-treated PC3 cells with miR-139 for 3 more days resulted in significantly up-regulated p62 compared to transfection with neg mimic (Figure 6A and B). Transcriptome analysis of PC3 or Du145 cells transfected with miR-139 for 4 days confirmed these results, with RNA expression of p62 gene, SQSTM1, increased approximately 2-fold in both cell lines (Figure 6C). These results suggest that prolonged miR-139 treatment of PC3 cells resulted in a block in autophagic flux.

The autophagosomal protein LC3B-II is ultimately degraded inside the autolysosome upon autophagy flux (23). However, LC3B-II up-regulation was sustained by miR-139 in PC3 cells, suggesting that either autophagy initiation is stimulated or autophagic flux is blocked and vesicles accumulate. In order to discriminate between these two scenarios, the utilization of CQ which blocks autophagic flux was performed. Treatment of PC3 cells with either miR-139 mimic or CQ resulted in accumulation of LC3B-II to similar levels as compared to neg mimic (Figures 6D and E). However, cotreatment of PC3 cells with miR-139 and CQ did not further increase levels of LC3B-II over CQ alone. Thus, the LC3B-II results combined with the p62 accumulation suggest that indeed, miR-139 treatment of PC3 cells results in incomplete autophagy, with a block in autophagic flux.

miR-139 induces cell death. In our previous study, we showed that miR-139 inhibited cell proliferation in both PC3 and Du145 cells, with cells arrested in $\mathrm{G}_{2} / \mathrm{M}$ phase of cell 


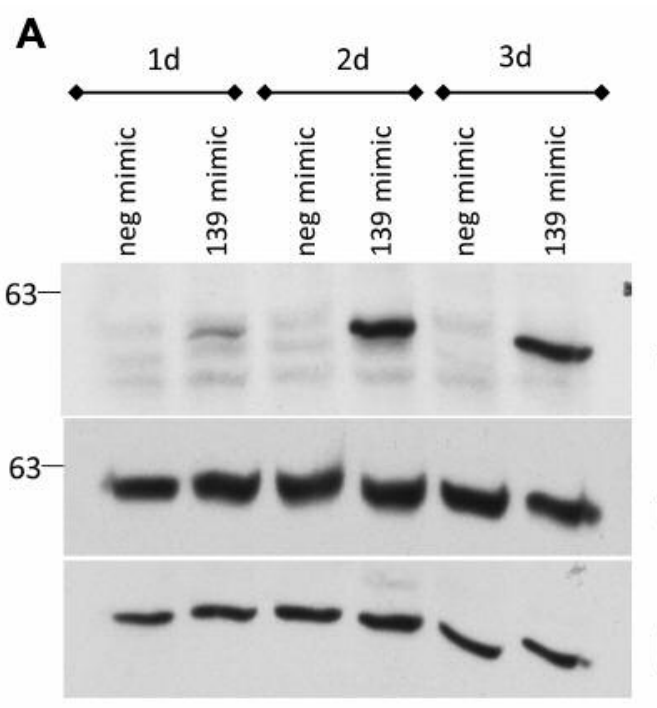

C

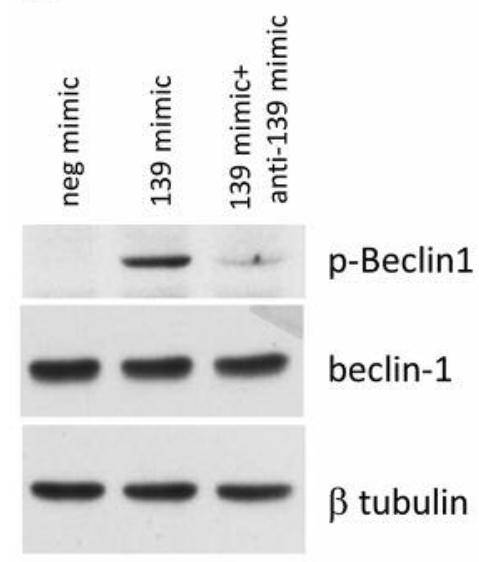

D

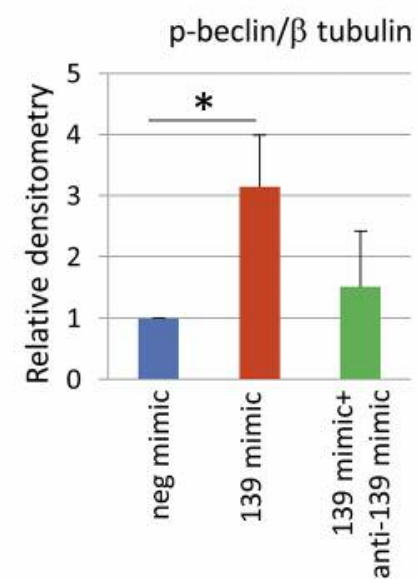

B

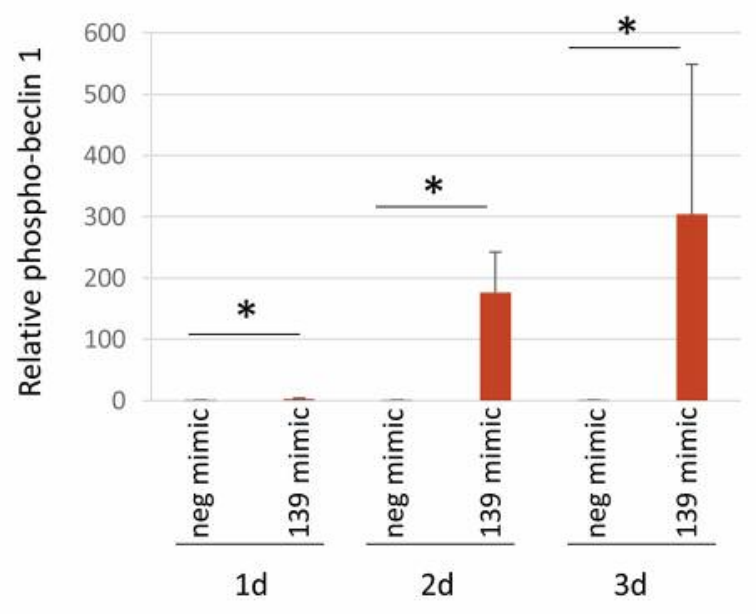

E 
variety of mechanisms. Cleavage of PARP-1 by caspases is considered a hallmark of apoptosis $(26,27)$. Thus, we examined the lysates for cleaved PARP-1. Transfection of miR-139 in both PC3 and Du145 up-regulated cleaved PARP-1 (Figures 7C and D). These results suggest that miR139-treatment of PCa cells lead to cell death mediated in part by apoptosis. Taking into account our previous data showing decreased proliferation upon miR-139 treatment, miR-139 likely is both reducing proliferation and increasing cell death in PCa cells.

miR-139 affects cell autophagy and apoptosis through the p38 and Erk1/2 pathway. Previous studies have indicated that p38 and Erk1/2, two important MAPK family members, are important upstream signaling proteins involved in regulating $\mathrm{mTOR}$ activity and necessary for the induction of autophagy $(28,29)$. However, both Erk1/2 and p38 can also up-regulate apoptotic pathways, depending on the stimuli (30). Western blotting results showed that miR-139 treatment of PC3 cells for 3 days activated Erk1/2 by increasing its phosphorylation (Figure 8A and $\mathrm{B}$ ). This activation could be inhibited by addition of mir-139 antagomir. Similarly, miR139 treatment of PC3 cells for 3 days also resulted in phosphorylated or activated p38 MAPK (Figure 8A and D). The protein levels were quantified as p-p38/p38 and pErk/Erk expression ratios (Figures $8 \mathrm{~B}$ and D). Thus, activation of both Erk1/2 and p38 may be partially responsible for the increased cell death associated with miR139 treatment.

\section{Discussion}

Previously, we described that miR-139 inhibited prostate cancer cell growth through down-regulation of targets, AXL and IGF1R, resulting in cell cycle arrest (10). In this study, we extended the growth inhibitory mechanisms and discovered that miR-139 treatment of prostate cancer cells induced morphology changes. Alterations in morphology of PC3 cells treated with miR-139 strongly resembled those seen in cells undergoing autophagy. Autophagy was then confirmed by visualization of increased LC3B puncta with miR-139 treatment of PC3 cells, along with up-regulation of autophagy-associated proteins, LC3B-II, phospho-beclin 1, and p62 by immunoblotting.

The PI3K/Akt pathway is known to inhibit autophagy through the activation of mTOR, which is the gatekeeper for autophagy initiation $(21,22)$. We have previously shown that activation of Akt is inhibited by miR-139 treatment of PCa cells (10). Herein, we take this further and show that expression of the downstream protein, mTOR, is also inhibited by miR-139. At the protein and mRNA level. We previously identified both AXL and IGF1R as targets of miR-139 in prostate cancer cells (10). Both AXL and IGF1R activate the PI3K/Akt axis, and as such, the inhibition of both such targets by miR-139 would likely result in the inhibition of the downstream mTOR protein as well. Perhaps sustained inhibition of the PI3K/Akt/mTOR axis ultimately down-regulates mTOR at the protein level. In support of this, the inhibition of both p-mTOR and mTOR protein expression by miR-139 is more evident at day 3 than day 1 (Figure 5A and B).

Autophagy is a cellular degradation and recycling process which is induced in response to environmental signals such as nutrient deprivation, hormones and microbial pathogens (31). While autophagy is usually a cytoprotective condition, an imbalance in cellular metabolism may cause excessive autophagic activation, inducing cell death (32). We previously showed that miR-139 treatment of prostate cancer cells inhibits cell growth. Here we show in addition to inducing autophagy, prolonged miR-139 treatment, whereby cells are treated for 2 days with miR-139, and then reseeded and retransfected for a further 3 days, results in significant cell death after 5 days (Figure 7A and B). This death was associated with up-regulated cleaved PARP, which is typically associated with apoptosis. Interestingly, PARP-1 activation interfaces with signaling pathways known to promote autophagy (33). It may be that miR-139 induced cell death in PC3 cells through excessive autophagy.

LC3B puncta and LC3B-II expression were increased upon miR-139 treatment of PC3 cells. Augmented LC3B-II expression is indicative of either increased autophagy initiation or a block in autophagosome turnover. To further discriminate between these 2 potential mechanisms, PC3 cells were treated with miR-139 and CQ. CQ inhibits autophagy flux by raising the $\mathrm{pH}$ within the lumen of lysosomes and/or autolysosomes and therefore compromises autophagic degradation, leading to a further accumulation of LC3B-II (34). Any LC3B-II accumulation beyond that observed with CQ alone is then attributed to enhanced autophagy initiation. Treatment with miR-139 together with CQ did not increase the levels of LC3B-II expression over levels observed with CQ alone, suggesting that autophagic flux was blocked. Activation of autophagy results in decreased expression of SQSTM1/p62, because of its accumulation in autophagosomes and subsequent degradation by lysosomes (23). We observed increased expression of SQSTM1/p62 upon miR-139 treatment of PC3 cells, particularly at the later time point at both the RNA and protein level (Figure 6A-C). This data further supported the idea that in addition to stimulating autophagosome formation, miR-139 also blocks autophagic flux at the late stage. Enhanced incomplete autophagy, as a result of treatment with an autophagy inducer and inhibitor, leads to cell degeneration followed by cell death (35). Since miR-139 treatment may be seen as both an autophagic inducer and inhibitor, cell death may have resulted by a similar method 
A

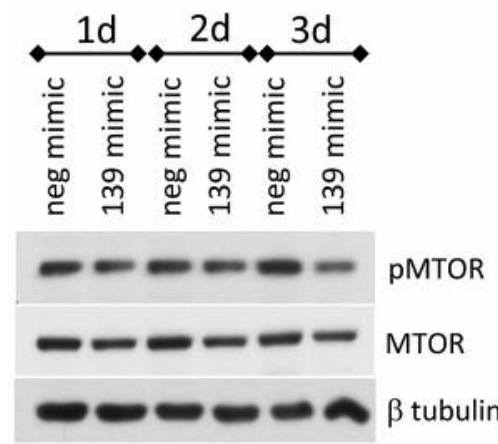

C

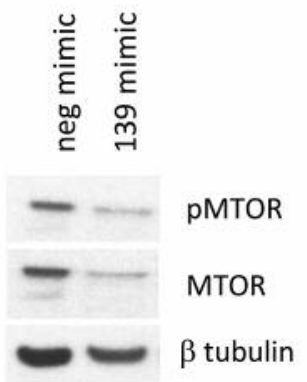

B

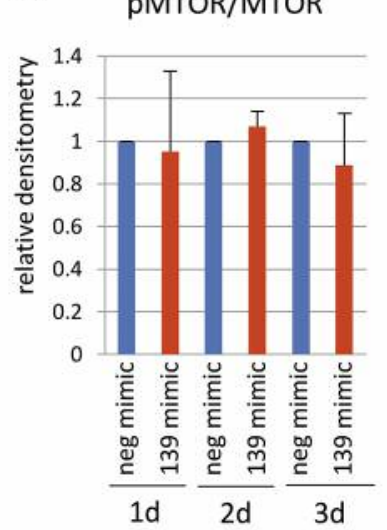

$\mathrm{pMTOR} / \beta$ tubulin

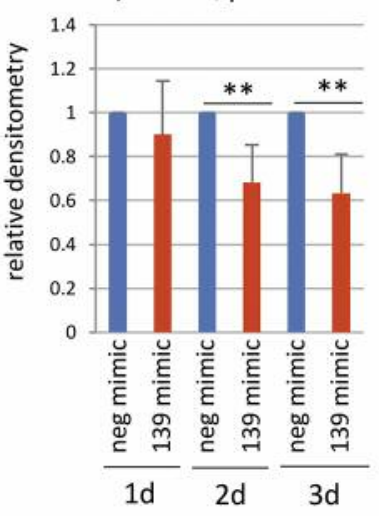

$\mathrm{mTOR} / \beta$ tubulin

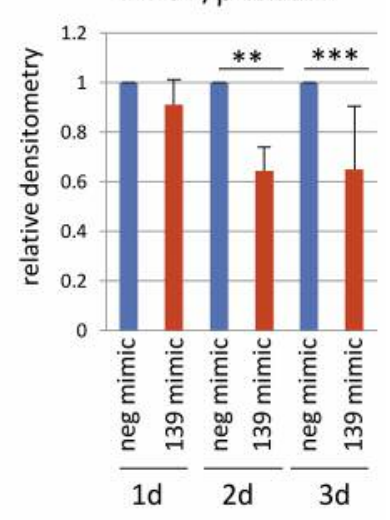

D $\mathrm{pMTOR} / \beta$ tubulin

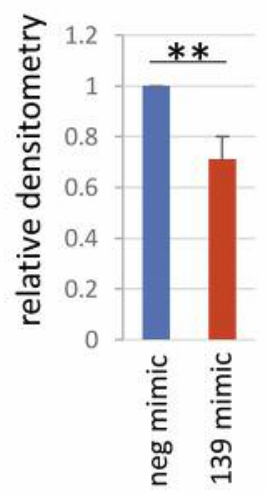

E

mTOR expression

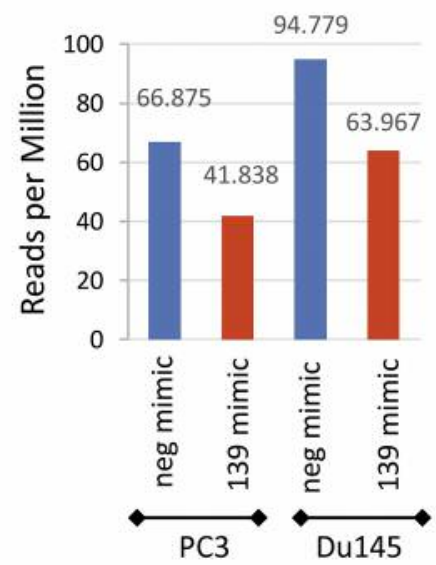

Figure 5. (A) PC3 cells were transiently transfected with either miR-139 mimic or negative control (neg) mimic for 1, 2 and 3 days. Western blots (WB) were performed by incubating with p-MTOR antibody, stripped and reprobed with total MTOR antibody, and stripped and re-probed with $\beta$ tubulin antibody. (B) WB from (A) was quantified using densitometry. Protein levels of pMTOR were compared to mTOR to assess for activation of mTOR. Protein levels of $p-M T O R$ and MTOR were also separately compared to $\beta$ tubulin for loading controls. Data are presented as a mean $+S D$ of the mean of at least three independent experiments and p-values determined by the unpaired t-test $(* p<0.05 ; * * p<0.01 ; * * * p<0.001)$. (C) Dul45 cells were transiently transfected for 3 days as in (A). (D) WB from $(C)$ was quantified as in $(B)$. (E) PC3 and Du145 cells were transiently transfected for 4 days with miR-139 mimic or negative control mimic. RNA was extracted, reverse transcribed and subjected to whole RNA transcriptome sequencing. Reads per million of mTOR expression are shown in graph with actual values displayed above each bar.

in our study. Du145 cells were incapable of up-regulating LC3B-II in response to either miR-139 or CQ, which has been shown to be due to a deficiency in full-length ATG5 protein, resulting in impaired autophagy (15). The lack of wild-type ATG5 was associated with SQSTM1/p62 accumulation in Du145 cells. Treatment with the histone deacetylase (HDAC) inhibitor, valproic acid (VPA), which induced autophagy in PC3 and LNCaP cells, did not significantly change the level of p62 in Du145 cells, which suggested that autophagy-dependent p62 degradation was impaired in this cell line (15). In our study, we also observed a very high level of p62 expression in Du145 cells in the presence of negative mimic, and this expression was further increased with miR-139 treatment or CQ (Figure 3E). These results suggest that miR-139 treatment of Du145 cells further exacerbating the autophagic block that already exists in these cells. Perhaps this is why treatment of Du 145 cells for 5 days with miR-139 induced significant cell death $(75 \%)$, which was even more pronounced compared to miR-139 treatment of PC3 cells (Figure 7B).

Autophagy has contradictory roles in cancer. Autophagy was initially considered a tumor-suppression mechanism, 
A

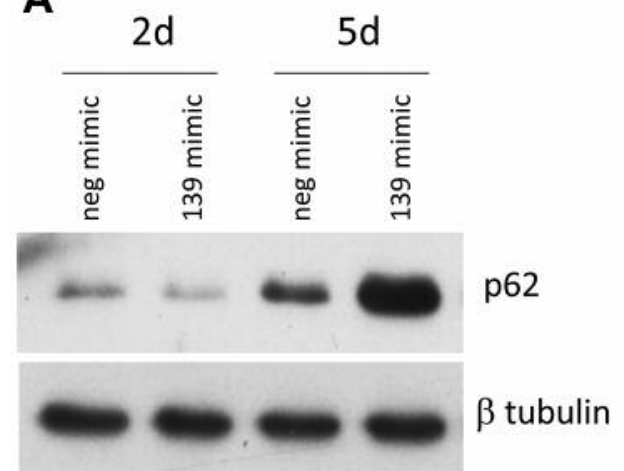

B

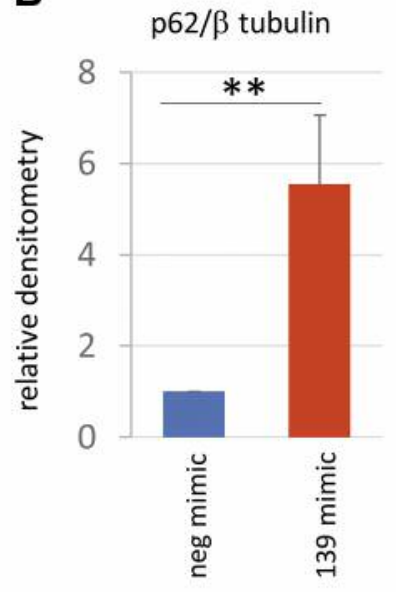

C

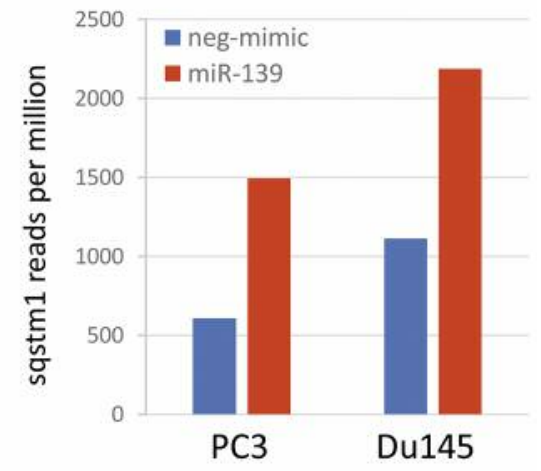

D

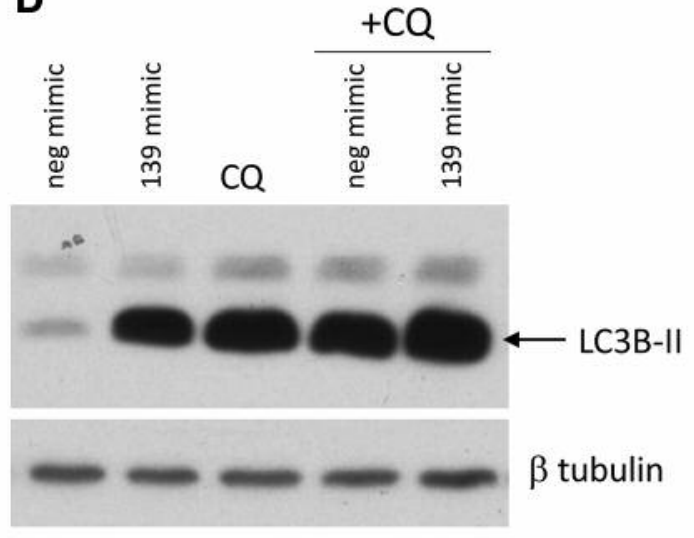

E

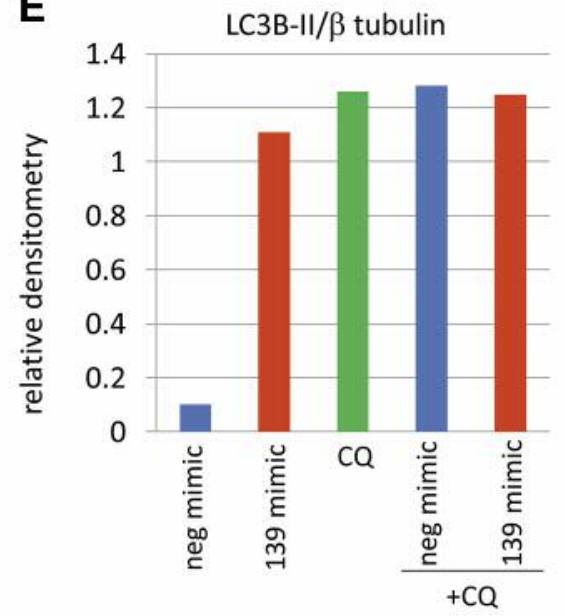

Figure 6. (A) PC3 cells were transiently transfected with either miR-139 mimic or negative control (neg) mimic for 2 and 5 days. Western blots (WB) were performed on cell lysates from each time point with anti-p62 antibodies, followed by stripping and re-probing with $\beta$ tubulin antibodies for loading controls. WB is representative of at least 3 separate experiments. (B) WBs of p62 from PC3 cells treated for 5 days with miR-139 were quantified from at least 3 separate experiments, using $\beta$-tubulin as loading control. (C) PC 3 and Dul45 cells were transiently transfected for 4 days with either miR-139 or negative control mimic. RNA was extracted, reverse transcribed and subjected to whole RNA transcriptome sequencing. Reads per million of SQSTM1 expression are depicted on graph. (D) PC3 cells were seeded overnight, then transfected with either miR-139 mimic, neg mimic, $C Q(50 \mu M)$, or a combination of $C Q$ and miR-139 mimic or $C Q$ and neg mimic for 3 days. WB were developed with anti-LC3 antibodies, and $\beta$ tubulin for loading controls. A black arrow points to the LC3B-II band. (E) WB from (D) was quantified using densitometry. Protein levels of LC3B-II were compared to $\beta$ tubulin loading control.

owing to the fact that the essential autophagy gene, BECN1 (beclin 1) was monoallelically lost in $40 \%$ to $75 \%$ of human prostate, breast and ovarian cancers (36-38). However, autophagy has been identified as a survival mechanism across many tumour types (39-42). Furthermore, autophagy can be used by cancer cells as a survival strategy during therapeutic interventions (43). Autophagy in cancer cells has been shown to increase apoptotic and caspase-independent cell death (44-46). However, autophagy tends to sustain cell viability in cancer cells with defects in apoptosis $(44,47-49)$.
Clearly, autophagy has a context-dependent role in cancer development and treatment resistance.

In prostate cancer, autophagy is often impaired due to either activation of the PI3K/Akt/mTOR pathway, or through allelic loss of the essential autophagy gene beclin 1 (32). In our study, the induction of autophagy by miR-139 clearly was tumor suppressive in $\mathrm{PCa}$ cells, mechanistically proceeding in part through inhibition of the PI3K/Akt/mTOR pathway. However, one could argue that miR-139 does not induce complete autophagy, and that blocking autophagy flux is the 

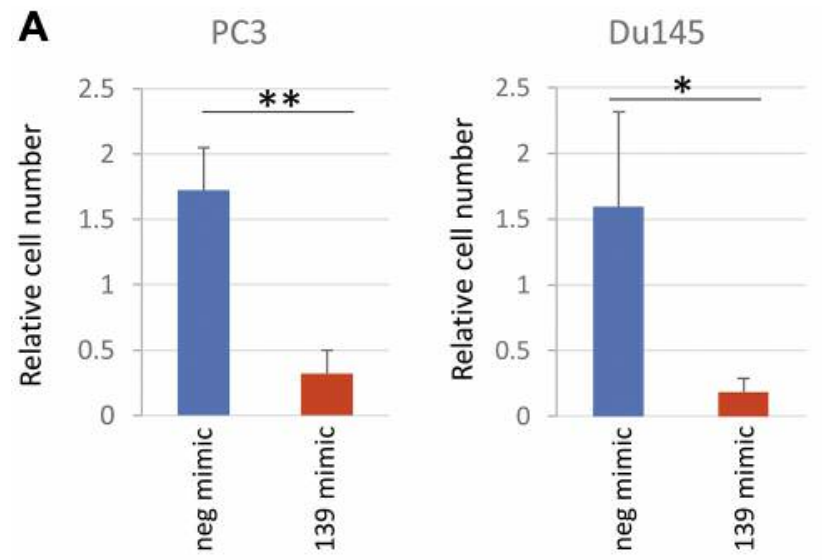

C

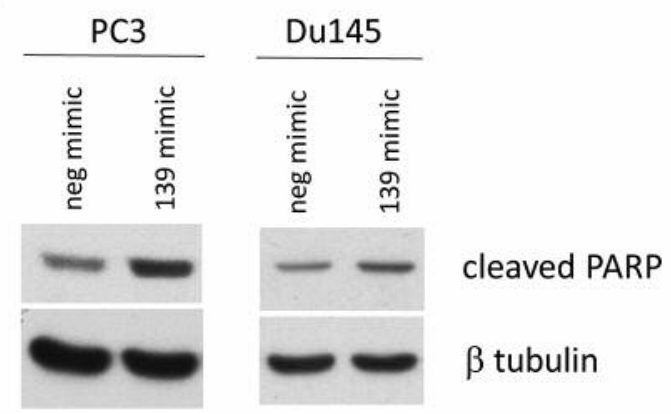

B
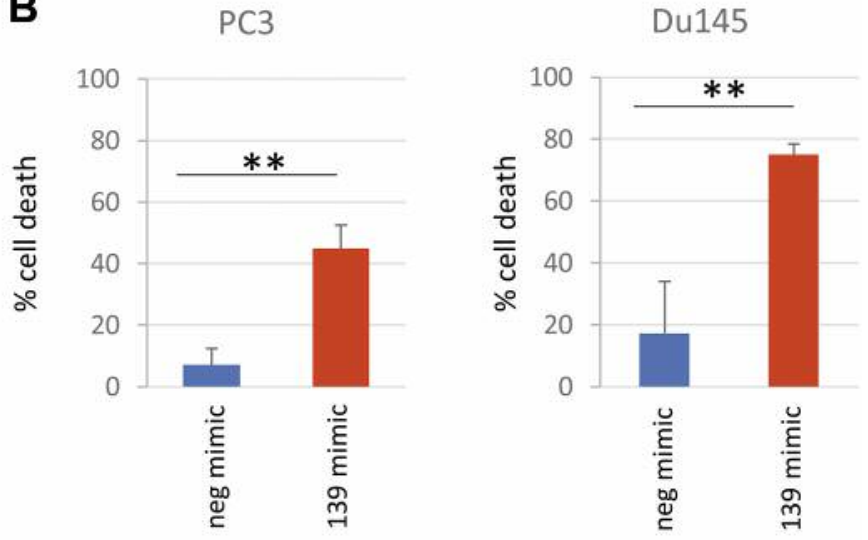

D

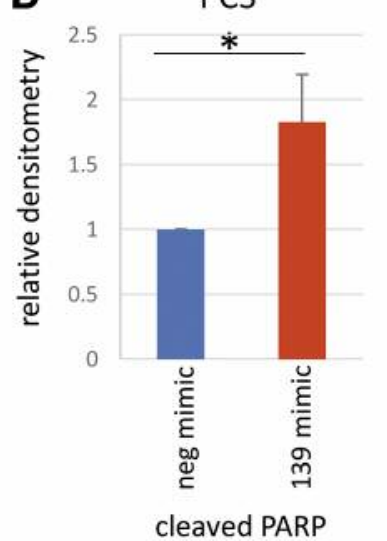

Du145

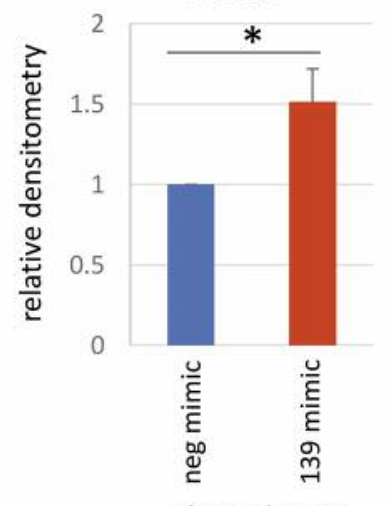

cleaved PARP

Figure 7. (A) PC3 or Du145 cells were transiently transfected with either miR-139 mimic or neg mimic for 2 days, reseeded and retransfected for 3 more days. Cells were harvested and counted at day 5. (B) Percentage of dead cells from (A) were calculated by counting the number of blue cells labeled by trypan blue, as a percentage of total cells (alive and dead) tabulated. (C) PC3 and Du145 cells were transiently transfected with miR-139 mimic or neg mimic for 1-2 days. Western blots (WB) were performed with cleaved PARP and $\beta$ tubulin. (D) WB from (C) was quantified using densitometry. Protein levels of cleaved PARP were compared to $\beta$ tubulin loading control. Data are presented as the mean+SD of the mean of three independent experiments, and p-values determined by the unpaired 2 tailed t-test $\left({ }^{*} p<0.05 ; * * p<0.01 ; * * * p<0.001\right)$.

actual tumor suppressive mechanism. Alternatively, it could be the combination of enhanced, sustained autophagy together with autophagic flux blockade, as was observed in one study (50). Inhibition of autophagic flux in another study lead to the accumulation of dysfunctional mitochondria and increased ROS formation, resulting in apoptosis (51).

Another novel cytotoxic mechanism involving autophagic flux blockade was observed with the dopamine agonist, cabergoline $(\mathrm{CAB})$ in rat pituitary tumor cells (52). CAB triggered autophagy at first through inhibiting mTOR pathways, but then dramatically increased lysosomal acidity, impairing lysosomal degradation within autolysosomes resulted in disrupted autophagic flux. Following autophagic flux blockade, $\mathrm{CAB}$ converted autophagy into a cell death mechanism.
In the rat pituitary tumor cells, CAB-induced cell death involved both apoptotic and autophagic pathways, which can coexist as a consequence of intracytoplasmic release of lysosomal enzymes (52). Thus, persistence of autophagy blockade disrupts the balance between autophagosome production and degradation capability, ultimately leading to autophagic cell death. In our study, miR-139 treatment of prostate cancer cells may have induced autophagic cell death in a similar fashion.

The anti-cancer drug sunitinib induced autophagic cell death and apoptosis in PCa cell lines (52). Autophagy was promoted by sunitinib through activation of Erk1/2 and inhibition of mTOR, similar to what we observed with miR-139 treatment. Constitutive activation of Erk1/2 has been shown to induce a 
A

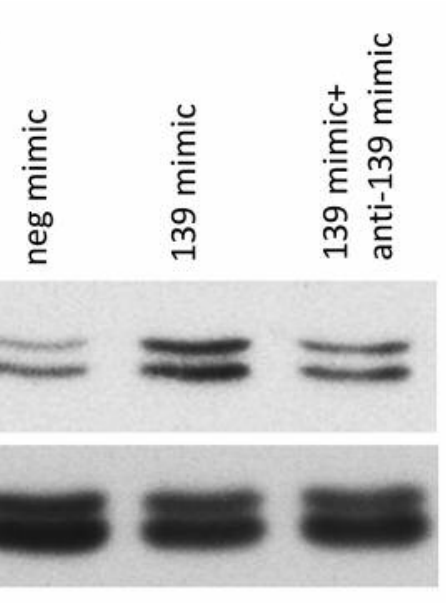

C

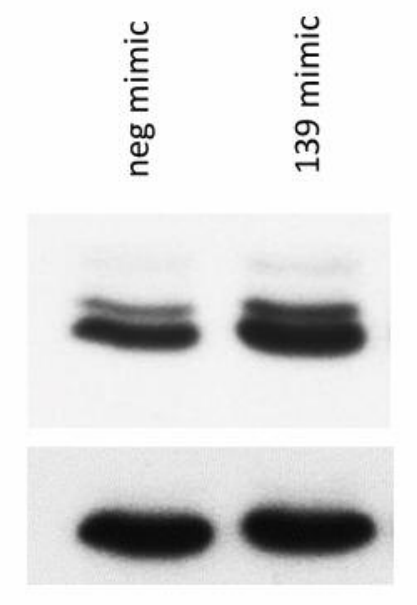

B

p-Erk1/2/Erk1/2

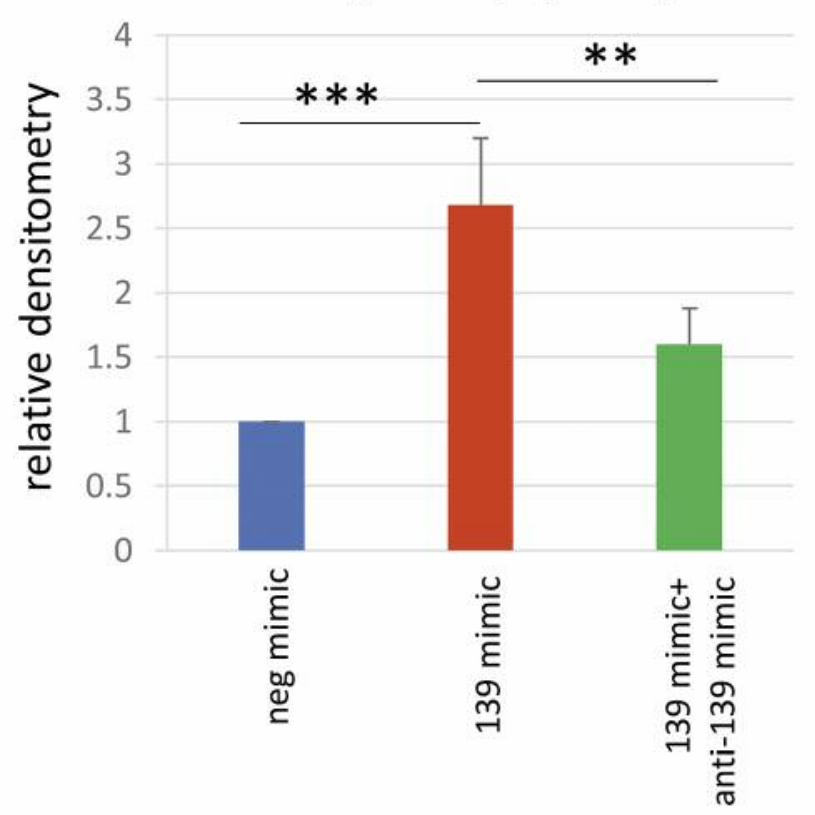

D

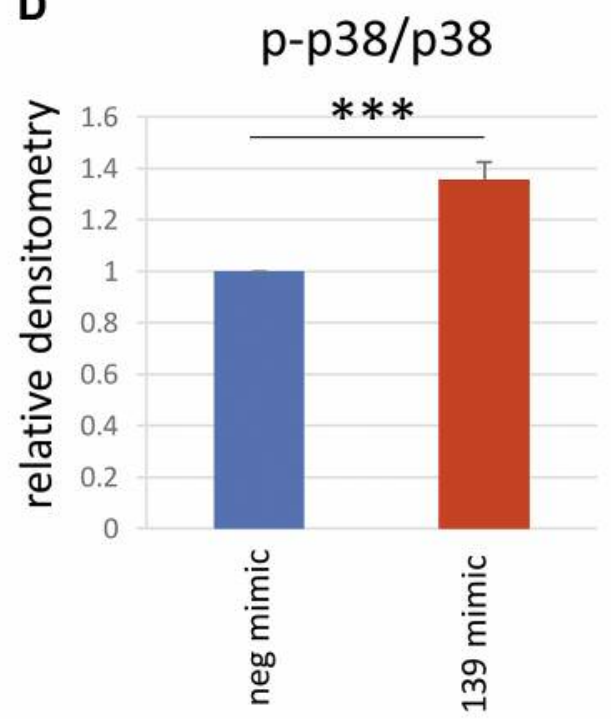

Figure 8. (A) PC3 cells were transiently transfected for 3 days with either miR-139 mimic, neg mimic or miR-139 mimic combined with miR-139 antagomir, as described in Figure 4C. Western blots (WB) were performed by staining with anti-phospho-ERK1/2 antibodies, followed by stripping and reprobing membranes with total ERK1/2 antibodies. (B) WB from (A) was quantified using densitometry. Protein levels of phospho-ERK1/2 were compared with total ERK1/2 levels. Blue bars represent transfection with neg mimic; red bars represent transfection with miR-139; green bars represent transfection with both miR-139 mimic and miR-139 antagomir. (C) PC3 cells were transiently transfected for 3 days with either miR-139 mimic or neg mimic. WB were performed by staining with with phospho-p38 antibodies, stripped and reprobed with total p38 antibodies. (D) WB from $(C)$ was quantified using densitometry. Expression levels of phospho-p38 were compared to total $p 38$. Data are presented as the mean $+S D$ of the mean of at least three independent experiments, and $p$ values determined by the unpaired 2 tailed t-test $(* p<0.05 ; * * p<0.01 ; * * * p<0.001)$.

form of cell death that correlated with extensive cell rounding and the formation of cytoplasmic macrovacuoles, which pushed the nucleus and cytoplasm to the side of the dying cell (53). This morphology was thought to represent autophagic programmed cell death, but also of paraptosis, a form of caspase-independent cell death associated with cytoplasmic vacuolization (54). We showed that miR-139 treatment of PC3 cells activated both Erk1/2 and p38 MAPK. P38 MAPK is 
strongly activated by environmental and genotoxic stresses (55). Many chemotherapeutic agents require p38 activation for induction of apoptosis (56). P38 MAPK can also mediate autophagy in response to chemotherapeutic agents (30). Thus, p38 is capable of regulating both apoptosis and autophagy (57).

A correlation between autophagy and miR-139 was shown in one study in cancer cells. Sodium butyrate $(\mathrm{NaB})$, an HDAC inhibitor, promoted AMPK/mTOR pathway-activated autophagy through up-regulation of miR-139-5p/Bmi-1 axis and mitochondria-mediated apoptosis in human bladder cancer cells (58). In this study, autophagy promoted apoptosis and contributed to cell death by $\mathrm{NaB}$ treatment. Our study is the first to show a correlation between miR-139 treatment and autophagy in PCa cell growth inhibition.

\section{Conclusion}

In this study, we expanded our previous observations that miR-139 treatment of PCa cells inhibits their growth. We showed that growth inhibition by miR-139 was associated with induction of autophagy in PC3 cells, through upregulation of beclin 1 phosphorylation and LC3-II expression. miR-139 treatment resulted in inhibition of mTOR expression in both PC3 and Du145 cells. Inhibition of the PI3K/Akt/mTOR pathway likely contributed to the induction of autophagy in PC3 cells. However, autophagy induction by miR-139 was not complete, as p62 expression remained elevated. Furthermore, prolonged miR-139 treatment induced massive cell death in both PC3 and Du145 cells. Our data suggests that miR-139 has the dual ability to simultaneously induce autophagy but block autophagic flux. Prolonged treatment by miR-139 led to persistent impairment of completion of autophagy, and inhibition of cell proliferation leading to massive cell death. Our previous study showed that high miR-139 expression was associated with lower incidence of recurrence and metastases (10). Taken together, perhaps the mechanism of miR-139-mediated growth inhibition leading to cell death described in this study may be occurring in these prostate cancer patients with high miR-139 expression, leading to their improved prognoses.

\section{Conflicts of Interest}

The Authors declare that there are no conflicts of interest.

\section{Author's Contributions}

T.B. performed molecular experiments, analyzed the data, and wrote the paper. R.N. designed the study, data analysis and acquisition of funding. Y.A. did the next-gen RNA-seq experiments and analysis. C.S analyzed immunohistochemistry slides. A.S. Provided the conceptual and technical guidance, designed the study, analyzed the data and revised it critically for important intellectual content.

\section{Acknowledgements}

This study was funded, in part, by the Edmond Odette Foundation, the Ajmera Family Chair in Urologic Oncology, and a generous philanthropic contribution from Archie and Betty McCallum.

\section{References}

1 Shoag $\mathrm{J}$ and Barbieri $\mathrm{C}$ : Clinical variability and molecular heterogeneity in prostate cancer. Asian J Androl 18(4): 543-548, 2016. PMID: 27080479. DOI: 10.4103/1008-682X.178852

2 Steele CB, Li J, Huang B and Weir HK: Prostate cancer survival in the United States by race and stage (2001-2009): Findings from the CONCORD-2 study. Cancer 123(Suppl24): 5160-5177, 2017. PMID: 29205313. DOI: 10.1002/cncr.31026

3 Humphrey PA: Gleason grading and prognostic factors in carcinoma of the prostate. Mod Pathol 17(3): 292-306, 2004. PMID: 14976540. DOI: 10.1038/modpathol.3800054

4 Loeb S, Bjurlin MA, Nicholson J, Tammela TL, Penson DF, Carter HB, Carroll $\mathrm{P}$ and Etzioni R: Overdiagnosis and overtreatment of prostate cancer. Eur Urol 65(6): 1046-1055, 2014. PMID: 24439788. DOI: 10.1016/j.eururo.2013.12.062

5 Bertoli G, Cava C and Castiglioni I: MicroRNAs as biomarkers for diagnosis, Prognosis and theranostics in prostate cancer. Int J Mol Sci 17(3): 421, 2016. PMID: 27011184. DOI: 10.3390/ ijms 17030421

6 Vanacore D, Boccellino M, Rossetti S, Cavaliere C, D'Aniello C, di Franco R, Romano FJ, Montanari M, la Mantia E, Piscitelli R, Nocerino F, Cappuccio F, Grimaldi G, Izzo A, Castaldo L, Pepe MF, Malzone MG, Iovane G, Ametrano G, Stiuso P, Quagliuolo L, Barberio D, Perdonà S, Muto $\mathrm{P}$, Montella $\mathrm{M}$, Maiolino $\mathrm{P}$, Veneziani BM, Botti G, Caraglia M and Facchini G: MicroRNAs in prostate cancer: An overview. Oncotarget 8(30): 50240-50251, 2017. PMID: 28445135. DOI: 10.18632/oncotarget.16933

7 Nam RK, Amemiya Y, Benatar T, Wallis CJD, StojcicBendavid J, Bacopulos S, Sherman C, Sugar L, Naeim M, Yang W, Zhang A, Klotz LH, Narod SA and Seth A: Identification and validation of a five MicroRNA signature predictive of prostate cancer recurrence and metastasis: A cohort study. J Cancer 6(11): 1160-1071, 2015. PMID: 26516365. DOI: $10.7150 /$ jca. 13397

8 Nam RK, Benatar T, Amemiya Y, Wallis CJD, Romero JM, Tsagaris M, Sherman C, Sugar L and Seth A: MicroRNA-652 induces NED in LNCaP and EMT in PC3 prostate cancer cells. Oncotarget 9(27): 19159-19176, 2018. PMID: 29721191. DOI: 10.18632/oncotarget.24937

9 Nam RK, Benatar T, Wallis CJD, Amemiya Y, Yang W, Garbens A, Naeim M, Sherman C, Sugar L and Seth A: MiR-301a regulates E-cadherin expression and is predictive of prostate cancer recurrence. Prostate 76(10): 869-884, 2016. PMID: 26990571. DOI: $10.1002 /$ pros.23177

10 Nam RK, Benatar T, Wallis CJD, Kobylecky E, Amemiya Y, Sherman C and Seth A: MicroRNA-139 is a predictor of prostate cancer recurrence and inhibits growth and migration of prostate cancer cells through cell cycle arrest and targeting IGF1R and AXL. Prostate 79(12): 1422-1438, 2019. PMID: 31269290. DOI: 10.1002/pros.23871

11 Mizushima N and Komatsu M: Autophagy: Renovation of cells and tissues. Cell 147(4): 728-741, 2011. PMID: 22078875. DOI: 10.1016/j.cell.2011.10.026 
12 Gozuacik D and Kimchi A: Autophagy and cell death. Curr Top in Dev Biol 78: 217-245, 2007. PMID: 17338918. DOI: 10.1016/S0070-2153(06)78006-1

13 Tanida I, Ueno T and Kominami E: LC3 conjugation system in mammalian autophagy. Int J Biochem Cell Biol 36(12): 25032518, 2004. PMID: 15325588. DOI: 10.1016/j.biocel.2004.05.009

14 Mizushima N, Yamamoto A, Hatano M, Kobayashi Y, Kabey Y, Suzuki K, Tokuhis T, Ohsumi Y and Yoshimori T: Dissection of autophagosome formation using Apg5-deficient mouse embryonic stem cells. J Cell Biol 152(4): 657-668, 2001. PMID: 11266458. DOI: $10.1083 /$ jcb.152.4.657

15 Ouyang DY, Xu LH, He XH, Zhang YT, Zeng LH, Cai JY and Ren S: Autophagy is differentially induced in prostate cancer LNCaP, DU145 and PC-3 cells via distinct splicing profiles of ATG5. Autophagy 9(1): 20-32, 2013. PMID: 23075929. DOI: 10.4161 /auto. 22397

16 Liang XH, Kleeman LK, Jiang HH, Gordon G, Goldman JE, Berry G, Herman B and Levine B: Protection against fatal sindbis virus encephalitis by Beclin, a novel Bcl-2-interacting protein. J Virol 72(11): 8586-8596, 1998. PMID: 9765397. DOI: 10.1128/jvi.72.11.8586-8596.1998

17 Liang C, Lee JS, Inn KS, Gack MU, Li Q, Roberts EA, Vergne I, Deretic V, Feng P, Akazawa C and Jung JU: Beclin1-binding UVRAG targets the class $\mathrm{C}$ Vps complex to coordinate autophagosome maturation and endocytic trafficking. Nat Cell Biol 10(7): 776-787, 2008. PMID: 18552835. DOI: 10.1038/ncb1740

18 Matsunaga K, Saitoh T, Tabata K, Omori H, Satoh T, Kurotori N, Maejima I, Shirahama-Noda K, Ichimura T, Isobe T, Akira S, Noda $\mathrm{T}$ and Yoshimori T: Two Beclin 1-binding proteins, Atg14L and Rubicon, reciprocally regulate autophagy at different stages. Nat Cell Biol 11(4): 385-396, 2009. PMID: 19270696. DOI: $10.1038 /$ ncb1846

19 Zhong Y, Wang QJ, Li X, Yan Y, Backer JM, Chait BT, Heintz $\mathrm{N}$ and Yue $\mathrm{Z}$ : Distinct regulation of autophagic activity by Atg14L and Rubicon associated with Beclin 1-phosphatidylinositol-3-kinase complex. Nat Cell Biol 11(4): 468-476, 2009. PMID: 19270693. DOI: $10.1038 /$ ncb1854

20 Abrahamsen H, Stenmark H and Platta HW: Ubiquitination and phosphorylation of Beclin 1 and its binding partners: Tuning class III phosphatidylinositol 3-kinase activity and tumor suppression. FEBS Lett 586(11): 1584-1591, 2012. PMID: 22673570. DOI: 10.1016/j.febslet.2012.04.046

21 Codogno P and Meijer AJ: Autophagy and signaling: Their role in cell survival and cell death. Cell Death Diff 12(Suppl2): 15091518, 2005. PMID: 16247498. DOI: 10.1038/sj.cdd.4401751

22 Cao C, Subhawong T, Albert JM, Kim KW, Geng L, Sekhar KR, Gi YJ and Lu B: Inhibition of mammalian target of rapamycin or apoptotic pathway induces autophagy and radiosensitizes PTEN null prostate cancer cells. Cancer Res 66(20): 10040-10047, 2006. PMID: 17047067. DOI: 10.1158/0008-5472.CAN-06-0802

23 Bjørkøy G, Lamark T, Brech A, Outzen H, Perander M, Øvervatn A, Stenmark H and Johansen T: p62/SQSTM1 forms protein aggregates degraded by autophagy and has a protective effect on huntingtin-induced cell death. J Cell Biol 171(4): 603614, 2005. PMID: 16286508. DOI: 10.1083/jcb.200507002

24 Pankiv S, Clausen TH, Lamark T, Brech A, Bruun JA, Outzen H, Øvervatn A, Bjørkøy G and Johansen T: p62/SQSTM1 binds directly to Atg8/LC3 to facilitate degradation of ubiquitinated protein aggregates by autophagy. J Biol Chem 282(33): 2413124145, 2007. PMID: 17580304. DOI: 10.1074/jbc.M702824200
25 Korolchuk VI, Menzies FM and Rubinsztein DC: A novel link between autophagy and the ubiquitin-proteasome system. Autophagy 5(6): 862-863, 2009. PMID: 19458478. DOI: 10.4161/auto.8840

26 Kaufmann SH, Desnoyers S, Ottaviano Y, Davidson NE and Poirier GG: Specific proteolytic cleavage of poly(ADP-ribose) polymerase: An early marker of chemotherapy-induced apoptosis. Cancer Res 53(17): 3976-3985, 1993. PMID: 8358726.

27 Tewari M, Quan LT, O’Rourke K, Desnoyers S, Zeng Z, Beidler DR, Poirier GG, Salvesen GS and Dixit VM: Yama/CPP32 $\beta$, a mammalian homolog of CED-3, is a CrmA-inhibitable protease that cleaves the death substrate poly(ADP-ribose) polymerase. Cell 81(5): 801-809, 1995. PMID: 7774019. DOI: 10.1016/00928674(95)90541-3

28 Martinez-Lopez N and Singh R: ATGs: Scaffolds for MAPK/ERK signaling. Autophagy 10(3): 535-537, 2014. PMID: 24412893. DOI: $10.4161 /$ auto. 27642

29 Corcelle E, Djerbi N, Mari M, Nebout M, Fiorini C, Fénichel P, Hofman P, Poujeol P and Mograbi B: Control of the autophagy maturation step by the MAPK ERK and p38: Lessons from environmental carcinogens. Autophagy 3(1): 57-59, 2007. PMID: 17102581. DOI: 10.4161/auto.3424

30 Sui X, Kong N, Ye L, Han W, Zhou J, Zhang Q, He C and Pan $\mathrm{H}$ : P38 and JNK MAPK pathways control the balance of apoptosis and autophagy in response to chemotherapeutic agents. Cancer Lett 344(2): 174-179, 2014. PMID: 24333738. DOI: 10.1016/j.canlet.2013.11.019

31 Mizushima N, Levine B, Cuervo AM and Klionsky DJ: Autophagy fights disease through cellular self-digestion. Nature 451(7182): 1069-1075, 2008. PMID: 18305538. DOI: 10.1038/ nature06639

32 Mathew R, Karantza-Wadsworth V and White E: Role of autophagy in cancer. Nat Rev Cancer 7(12): 961-967, 2007. PMID: 17972889. DOI: 10.1038/nrc2254

33 Muñoz-Gámez JA, Rodríguez-Vargas JM, Quiles-Pérez R, Aguilar-Quesada R, Martín-Oliva D, de Murcia G, de Murcia JM, Almendros A, Ruiz De Almodóvar M and Oliver FJ: PARP-1 is involved in autophagy induced by DNA damage. Autophagy $5(1)$ : 61-74, 2009. PMID: 19001878. DOI: 10.4161/auto.5.1.7272

34 Mauthe M, Orhon I, Rocchi C, Zhou X, Luhr M, Hijlkema KJ, Coppes RP, Engedal N, Mari M and Reggiori F: Chloroquine inhibits autophagic flux by decreasing autophagosome-lysosome fusion. Autophagy 14(8): 1435-1455, 2018. PMID: 29940786. DOI: $10.1080 / 15548627.2018 .1474314$

35 Nagelkerke A, Bussink J, Geurts-Moespot A, Sweep FCGJ and Span PN: Therapeutic targeting of autophagy in cancer. Part II: Pharmacological modulation of treatment-induced autophagy. Semin Cancer Biol 31: 99-105, 2015. PMID: 2433034. DOI: 10.1016/j.semcancer.2014.06.001

36 Aita VM, Liang XH, Murty VVVS, Pincus DL, Yu W, Cayanis E, Kalachikov S, Gilliam TC and Levine B: Cloning and genomic organization of beclin 1, a candidate tumor suppressor gene on chromosome 17q21. Genomics 59(1): 59-65, 1999. PMID: 10395800. DOI: 10.1006/geno.1999.5851

37 Choi AMK, Ryter SW and Levine B: Autophagy in human health and disease. New Engl J Med 368(7): 651-662, 2013. PMID: 23406030. DOI: 10.1056/nejmra1205406

38 Liang XH, Jackson S, Seaman M, Brown K, Kempkes B, Hibshoosh $\mathrm{H}$ and Levine B: Induction of autophagy and inhibition of tumorigenesis by beclin 1 . Nature 402(6762): 672676, 1999. PMID: 10604474. DOI: $10.1038 / 45257$ 
39 Altman JK, Szilard A, Goussetis DJ, Sassano A, Colamonici M, Gounaris E, Frankfurt O, Giles FJ, Eklund EA, Beauchamp EM and Platanias LC: Autophagy is a survival mechanism of acute myelogenous leukemia precursors during dual mTORC2/mTORC1 targeting. Clin Cancer Res 20(9): 2400-2409, 2014. PMID: 24610825. DOI: 10.1158/1078-0432.CCR-13-3218

40 Zhuang K, Guo H, Tang H, Yan Y, Zhang J, Zhang L, Han K and Zhang X: Gastrin enhances autophagy and promotes gastric carcinoma proliferation via inducing AMPKa. Oncol Res 25(8): 1399-1407, 2017. PMID: 28059052. DOI: 10.3727/096504016 X14823648620870

41 Masui A, Hamada M, Kameyama H, Wakabayashi K, Takasu A, Imai T, Iwai $\mathrm{S}$ and Yura Y: Autophagy as a survival mechanism for squamous cell carcinoma cells in endonuclease g-mediated apoptosis. PLoS ONE 11(9): e0162786, 2016. PMID: 27658240. DOI: $10.1371 /$ journal.pone.0162786

42 Tan Q, Wang M, Yu M, Zhang J, Bristow RG, Hill RP and Tannock IF: Role of autophagy as a survival mechanism for hypoxic cells in tumors. Neoplasia (United States) 18(6): $347-$ 355, 2016. PMID: 27292024. DOI: 10.1016/j.neo.2016.04.003

43 Chen N and Karantza V: Autophagy as a therapeutic target in cancer. Cancer Biol Ther 11(2): 157-168, 2011. PMID: 21228626. DOI: $10.4161 /$ cbt.11.2.14622

44 Karantza-Wadsworth V, Patel S, Kravchuk O, Chen G, Mathew $\mathrm{R}$, Jin S and White E: Autophagy mitigates metabolic stress and genome damage in mammary tumorigenesis. Genes Dev 21(13): 1621-1635, 2007. PMID: 17606641. DOI: 10.1101/gad.1565707

45 Boya P, González-Polo R-A, Casares N, Perfettini J-L, Dessen P, Larochette N, Métivier D, Meley D, Souquere S, Yoshimori T, Pierron G, Codogno P and Kroemer G: Inhibition of macroautophagy triggers apoptosis. Mol Cell Biol 25(3): 1025-1040, 2005. PMID: 15657430. DOI: 10.1128/mcb.25.3.1025-1040.2005

46 Colell A, Ricci JE, Tait S, Milasta S, Maurer U, Bouchier-Hayes L, Fitzgerald P, Guio-Carrion A, Waterhouse NJ, Li CW, Mari B, Barbry P, Newmeyer DD, Beere HM and Green DR: GAPDH and autophagy preserve survival after apoptotic cytochrome c release in the absence of caspase activation. Cell 129(5): 983997, 2007. PMID: 17540177. DOI: 10.1016/j.cell.2007.03.045

47 Degenhardt K, Mathew R, Beaudoin B, Bray K, Anderson D, Chen G, Mukherjee C, Shi Y, Gélinas C, Fan Y, Nelson DA, Jin S and White E: Autophagy promotes tumor cell survival and restricts necrosis, inflammation, and tumorigenesis. Cancer Cell 10(1): 5164, 2006. PMID: 16843265. DOI: 10.1016/j.ccr.2006.06.001

48 Lum JJ, Bauer DE, Kong M, Harris MH, Li C, Lindsten T and Thompson CB: Growth factor regulation of autophagy and cell survival in the absence of apoptosis. Cell 120(2): 237-248, 2005. PMID: 15680329. DOI: 10.1016/j.cell.2004.11.046

49 Mathew R, Kongara S, Beaudoin B, Karp CM, Bray K, Degenhardt K, Chen G, Jin S and White E: Autophagy suppresses tumor progression by limiting chromosomal instability. Genes Dev 21(11): 1367-1381, 2007. PMID: 17510285. DOI: $10.1101 / \mathrm{gad} .1545107$
50 Kucharewicz K, Dudkowska M, Zawadzka A, Ogrodnik M, Szczepankiewicz AA, Czarnocki Z and Sikora E: Simultaneous induction and blockade of autophagy by a single agent. Cell Death Dis 9(3): 353, 2018. PMID: 29500364. DOI: 10.1038/s41419-018-0383-6

51 Klose J, Stankov M v., Kleine M, Ramackers W, PanayotovaDimitrova D, Jäger MD, Klempnauer J, Winkler M, Bektas H, Behrens GMN and Vondran FWR: Inhibition of autophagic flux by salinomycin results in anti-cancer effect in hepatocellular carcinoma cells. PLoS One 9(5): e95970, 2014. PMID: 24816744. DOI: 10.1371/journal.pone.0095970

52 Lin SJ, Leng ZG, Guo YH, Cai L, Cai Y, Li N, Shang HB, Le WD, Zhao WG and Wu ZB: Suppression of mTOR pathway and induction of autophagy-dependent cell death by cabergoline. Oncotarget 6(36): 39329-39341, 2015. PMID: 26513171. DOI: 10.18632 /oncotarget.5744

53 Cagnol S and Chambard JC: ERK and cell death: Mechanisms of ERK-induced cell death - Apoptosis, autophagy and senescence. FEBS J 277(1): 2-21, 2010. PMID: 19843174. DOI: 10.1111/j.1742-4658.2009.07366.x

54 Sperandio S, Poksay K, de Belle I, Lafuente MJ, Liu B, Nasir J and Bredesen DE: Paraptosis: Mediation by MAP kinases and inhibition by AIP-1/Alix. Cell Death Diff 11(10): 1066-1075, 2004. PMID: 15195070. DOI: 10.1038/sj.cdd.4401465

55 Han J, Lee JD, Bibbs L and Ulevitch RJ: A MAP kinase targeted by endotoxin and hyperosmolarity in mammalian cells. Science 265(5173): 808-811, 1994. PMID: 7914033. DOI: 10.1126/ science. 7914033

56 Loesch M and Chen G: The p38 MAPK stress pathway as a tumor suppressor or more? Front Biosci 13: 3581-3593, 2008. PMID: 18508457. DOI: 10.2741/2951

57 Jiang Q, Li F, Shi K, Wu P, An J, Yang Y and Xu C: Involvement of p38 in signal switching from autophagy to apoptosis via the PERK/eIF2 $\alpha /$ ATF4 axis in selenite-treated NB4 cells. Cell Death Dis 5(5): e1270, 2014. PMID: 24874742. DOI: $10.1038 /$ cddis.2014.200

58 Wang F, Wu H, Fan M, Yu R, Zhang Y, Liu J, Zhou X, Cai Y, Huang $\mathrm{S}, \mathrm{Hu} Z$ and Jin $\mathrm{X}$ : Sodium butyrate inhibits migration and induces AMPK-mTOR pathway-dependent autophagy and ROS-mediated apoptosis via the miR-139-5p/Bmi-1 axis in human bladder cancer cells. FASEB J 34(3): 4266-4282, 2020. PMID: 31957111. DOI: 10.1096/fj.201902626R
Received October 7, 2020

Revised October 19, 2020

Accepted October 23, 2020 